\title{
Methodological Incommensurability and Epistemic Relativism
}

\author{
Howard Sankey \\ University of Melbourne \\ chs@unimelb.edu.au
}

\begin{abstract}
This paper revisits one of the key ideas developed in The Structure of Scientific Revolutions. In particular, it explores the methodological form of incommensurability which may be found in the original edition of Structure. It is argued that such methodological incommensurability leads to a form of epistemic relativism. In later work, Kuhn moved away from the original idea of methodological incommensurability with his idea of a set of epistemic values that provides a basis for rational theory choice, but do not constitute an algorithm for such choice. The paper also explores the sceptical basis for the epistemic relativism of the original view that Kuhn proposes in Structure. It suggests that the main sceptical rationale for such relativism may be avoided by a particularist and naturalist conception of epistemic normativity. When this approach is combined with the appeal to external methodological standards endorsed by the later Kuhn and his critics, the epistemic relativism of Structure may be completely repudiated.
\end{abstract}

Keywords: methodological incommensurability; epistemic relativism; Pyrrhonian scepticism; particularism 


\section{Methodological Incommensurability and Epistemic Relativism}

\section{Introduction}

The thesis of Kuhn and Feyerabend that some theories or paradigms may be incommensurable raises well-known challenges for the philosophy of science. It leads to controversial implications with respect to the progress of science as well as the rationality of scientific theory choice. It has also been widely associated with relativism. In this paper, I investigate the relationship between one form of incommensurability and epistemic relativism.

As has been widely noted, Kuhn and Feyerabend did not employ the term 'incommensurable' to express the same thing. For Feyerabend, theories are incommensurable due to semantic variation between the vocabulary employed by theories. Kuhn's original claims about incommensurability included methodological and perceptual aspects in addition to semantic aspects, though he later restricted it to the semantic sphere. To reflect this difference, it is useful to distinguish between semantic and methodological forms of incommensurability. In this paper, I restrict attention to the methodological form of incommensurability. ${ }^{1}$

Relativism may likewise be understood in more than one way. The relativist may assert that truth is relative, that there are alternative adequate conceptual schemes, and even that reality depends on theory. But in this paper I will focus on the epistemic variety of relativism. According to epistemic relativism, the justification of belief depends upon the epistemic norms or

\footnotetext{
1 The distinction between semantic and methodological forms of incommensurability was introduced in the Introduction to Hoyningen-Huene and Sankey (2001, xiii-xv) to provide a basis for discussion of the topic of incommensurability.
} 
standards that are in place in a particular context (e.g. paradigm, time period, social milieu). To be justified in holding a belief is for the belief to be justified on the basis of the epistemic norms which operate in a particular context. As the operative epistemic norms may vary with context, what one is justified in believing is relative to the epistemic norms that are in place in a context. For the epistemic relativist, justification is relative to operative epistemic norms. ${ }^{2}$

In a recent series of papers, I have proposed a particularist, naturalistic approach to epistemic relativism based on an analysis of the relationship between relativism and Pyrrhonian scepticism. ${ }^{3}$ The purpose of the present paper is to articulate this approach in relation to the topic of incommensurability, and especially with regard to the relationship between methodological incommensurability and epistemic relativism. I wish to show that the argument from methodological incommensurability to epistemic relativism fails at least in part due to the sceptical nature of Kuhn's treatment of epistemic justification. But some preliminary exploration will be necessary before I am able to turn to that task.

The discussion that follows is divided into six sections. In section 2, I introduce the methodological form of incommensurability found in The Structure of Scientific Revolutions. In section 3, I consider the relation between methodological incommensurability and epistemic relativism. In section 4 , I outline a widespread criticism of methodological incommensurability and consider Kuhn's own response to this criticism in terms of non-algorithmic values. In section 5, I analyze Kuhn's treatment of the justification of methodological standards which forms the

\footnotetext{
${ }^{2}$ In addition to justified belief, the epistemic relativist may also wish to say that knowledge is relative to operative norms. But talk of knowledge raises the question of truth, since knowledge requires truth. I do not wish to enter into the question of relativism about truth in this paper. So I will set the issue of knowledge to one side, and focus instead on relativism about justified belief.

3 Sankey (2010), (2011) and (2012).
} 
basis of his epistemic relativism. In section 6, I draw a parallel between Kuhn's treatment of justification and the ancient Pyrrhonian problem of the criterion. Finally, in section 7, I conclude by sketching my preferred response to epistemic relativism on the basis of a particularist response to the problem of the criterion.

\section{Methodological incommensurability in Structure}

The idea of methodological incommensurability relates to the standards of theory appraisal that may be employed in choice between theories or paradigms. It rests on the assumption that there are no fixed or independent standards to which appeal may be made in the comparison of alternative theories. Instead, standards of theory appraisal depend upon and vary with theory or paradigm. Competing theories may therefore be incommensurable in the methodological sense because there are no shared or neutral standards on the basis of which choice between such theories may be made.

As I will show in a moment, the idea of methodological incommensurability may be found in The Structure of Scientific Revolutions. However, as has been widely recognized, Kuhn moved away from the idea in later work. In The Essential Tension, Kuhn allowed that there is a set of epistemic values which are characteristic of science. The values may be employed in the comparative appraisal of theories, though they do not comprise an algorithm of theory choice. ${ }^{4}$ For his part, Feyerabend's views about the justified violation of rules of method in the history of

\footnotetext{
${ }^{4}$ The principal reference for Kuhn's discussion of values is chapter 13 of The Essential Tension (1977, especially pp. 330-3), though Kuhn makes related comments in the Postscript to Structure (1996, pp. 184-6, 199-200), as well as (1970, pp. 261-2).
} 
science are broadly consonant with Kuhn's later views about method. ${ }^{5}$ But Feyerabend did not claim that theories are incommensurable due to lack of shared standards of theory appraisal. In light of Kuhn's change of mind and Feyerabend's failure to endorse the idea, I focus on Structure as the source for methodological incommensurability.

At one point in Structure, Kuhn makes passing reference to "commitments without which no man is a scientist" (1996, p. 42). As an example of such commitments, he mentions the concern to "understand the world and to extend the scope and precision with which it has been ordered" (1996, p. 42). Kuhn's remark suggests there are basic commitments which are necessary to be a scientist. But such commitments fall short of requiring a universal method for science and are too ill-defined to constitute a universal method in their own right. Apart from this one remark, and a brief mention of the "essential characteristics" of a scientific community (1996, p. 168), the overwhelming impression conveyed by Structure is that the methodological standards employed in science depend upon paradigm and are subject to variation with change of paradigm.

In Kuhn's model of science, the principal role of methodological standards relates to the puzzles which are the main focus of normal science. The standards take the form of rules of puzzle-solving adequacy which, along with the puzzles themselves, derive from the reigning paradigm. The rules employed in puzzle-solving include the basic laws of a paradigm, such as Newton's laws, which "help to set puzzles and to limit acceptable solutions" (1996, p. 40). They also include low-level rules for the use of instrumentation and the conduct of experiment, as well as underlying metaphysical commitments about the fundamental structure and nature of reality,

\footnotetext{
${ }^{5}$ For example, Feyerabend's view that all rules of method may be justifiably violated (e.g. 1993, p. 14) accords well with Kuhn's later view that criteria of theory choice function as values rather than as rules. A defeasible rule of method seems akin to a value which guides choice, and which may be overlooked in favour of another value.
} 
such as corpuscularism (1996, pp. 40-1). Because puzzles and rules of puzzle-solving derive from specific paradigms, a change of paradigm gives rise to a change in rules as well as to the puzzles addressed in normal science under the new paradigm.

Revolutionary transition between paradigms brings about change of conceptual framework for scientists who convert to the new paradigm, as well as an alteration of their perceptual experience of the world due to the influence of paradigm on perception. Both the change in conceptual framework and perception constitute important elements of Kuhn's broader notion of the incommensurability of paradigms. However, the focus in this paper is restricted to the methodological form of incommensurability. Methodological incommensurability arises specifically as a result of change in the rules that govern normal science which is brought about by change in the paradigm under which science is practiced. ${ }^{6}$

According to Kuhn, paradigms do not just tell us about the world. They also have implications about how to do science. Paradigms "are the source of the methods, problem-field, and standards of solution accepted by any mature scientific community at any given time" (1996, p. 103). New paradigms redefine their field. Problems which were the focus of research under the previous paradigm give way to new problems which are the center of attention of the new paradigm. At the same time, the standards which governed the solution of puzzles in the former paradigm are replaced by new standards within the new paradigm. As a result of such change of

\footnotetext{
${ }^{6}$ It might be objected that semantic, methodological and perceptual aspects of incommensurability should not be treated in isolation from each other, since Kuhn presents them as co-occurring. But, for one thing, Kuhn later came to treat semantic incommensurability in isolation from the other aspects which he originally associated with incommensurability. For another thing, the arguments for meaning variance, theory-dependence of perception and methodological change are distinct arguments, which draw on different sets of considerations and give rise to different implications. In my judgement, the different aspects of incommensurability are best treated as logically and conceptually distinct issues.
} 
problems and standards, Kuhn says, the normal science which follows a revolution "is not only incompatible but often actually incommensurable with that which has gone before" (1996, p. 103).

As Kuhn notes, the change in standards that accompanies a change of paradigm may have an effect on what is taken to be an acceptable explanation. What was an acceptable explanation in the context of an earlier paradigm may no longer be regarded as an acceptable explanation in the context of the later paradigm that replaces it. For example, the Aristotelian explanation that a stone falls to earth in order to return to its natural place at the centre of the universe was no longer an acceptable explanation in the context of corpuscularism. Such explanation came to be regarded as "mere tautological word-play" (1996, p. 104). Molière's parody of dormitive virtues reflected the sense that explanation in terms of such virtues was to be rejected as unscientific.

The effect of methodological incommensurability is most acute in the debate between proponents of alternative paradigms which occurs in the course of a scientific revolution. In paradigm debate, the standards employed by particular paradigms are unable to function in a neutral manner as arbiters of the choice between paradigms. As Kuhn writes, the choice between paradigms "cannot be determined merely by the evaluative procedures characteristic of normal science, for these depend in part upon a particular paradigm, and that paradigm is at issue" (1996, p. 94). In other words, the standards employed within a paradigm derive specifically from the paradigm. Because of their dependence upon the paradigm, they are unable to provide a neutral basis for choice between the paradigm and a competing paradigm within which alternative standards are employed. 
Absence of shared standards is an obstacle to debate between paradigms. Proponents of competing paradigms employ different standards and take different problems seriously. As a result, Kuhn says, they "talk through each other when debating the relative merits of their respective paradigms" (1996, p. 109). Because of the different standards and problems, there is no shared basis on which to form an agreed appraisal of rival paradigms. Thus, the resulting debate is characterized by arguments which proceed in a circular manner. For, as Kuhn notes, "each paradigm will be shown to satisfy more or less the criteria that it dictates for itself and to fall short of a few dictated by its opponent" (1996, pp. 109-10). Though a paradigm may satisfy its own standards, without shared standards that are applicable to both competing paradigms, no appeal to standards may resolve the debate.

In sum, methodological incommensurability emerges from Kuhn's discussion in Structure as incommensurability due to absence of common standards between paradigms. Given Kuhn's dismissal of extraparadigmatic standards at this stage in the development of his position, there are no common standards over and above the standards employed by individual paradigms which may adjudicate conflict between paradigms. The result is a debate in which the proponents of alternative paradigms talk past each other and employ circular arguments. It is no surprise, therefore, that Kuhn was often taken to hold that the choice between paradigms is unable to be resolved on a rational basis. The situation was only aggravated by his tendency to compare choice of paradigm to a gestalt shift or religious conversion (e.g. 1996, p. 150). ${ }^{7}$

\footnotetext{
${ }^{7}$ A number of influential interpretations of Kuhn emphasize the anti-rationalistic implications of the absence of shared standards. See, for example, Lakatos (1978, pp. 90-1), Scheffler (1967, pp. 78ff), Shapere (1984, p. 51) and Siegel (1987, pp. 51-4). For an opposing interpretation, see Doppelt (1982).
} 


\section{The route to relativism}

I turn now from the nature of methodological incommensurability to its relation to epistemic relativism. The route from methodological incommensurability to epistemic relativism is fairly direct. If methodological standards vary with paradigm, and there are no extraparadigmatic standards, epistemic relativism is the result.

The route to epistemic relativism proceeds via two aspects of methodological incommensurability. On the one hand, in each paradigm there is a set of rules which determines the adequacy of solutions to puzzles within the context of the paradigm. On the other hand, there are no extraparadigmatic standards of theory appraisal which may be used for an objective evaluation of competing paradigms. Because there are no common standards, it is not possible to decide between paradigms in an objective manner. There is no rational basis for choice of paradigm. But the situation is different once a paradigm is adopted. Within the context of a particular paradigm, the rules of puzzle solution constitute standards of rationality for scientists who work in the paradigm. Scientists who adopt a particular paradigm may form beliefs which are justified on the basis of the rules that are operative within the context of that paradigm.

On Kuhn's account of paradigm choice, it is not possible to rationally choose between competing paradigms. Rationality is internal to paradigm. It is paradigm-relative. Within the context of a given paradigm, scientists form beliefs on the basis of the rules that operate in that paradigm. Such beliefs are justified on the basis of those rules. Given the variation of operative standards between paradigms, scientists in competing paradigms may justifiably accept opposing beliefs on the basis of the different sets of rules employed in the paradigms which they accept. In 
this way, scientists who endorse alternative paradigms may be justified in accepting conflicting claims about the world. ${ }^{8}$ Because justified belief depends upon the norms which are operative within alternative paradigms, justified belief is relative to paradigm. It is relative to the rules that are in place within particular paradigms.

The route to relativism that I have just traced reflects a significant feature of the relationship between incommensurability and relativism. As should be apparent, methodological incommensurability and epistemic relativism are not the same thing. Rather, methodological incommensurability serves as point of departure for the route to epistemic relativism. Because there are no common standards of theory appraisal, there is no objective basis for the choice between competing paradigms. It is the lack of an objective basis for paradigm choice which fundamentally underlies the epistemic relativism at the heart of Kuhn's account of scientific change. Methodological incommensurability is therefore part of the case for epistemic relativism.

\section{Methodological incommensurability and external standards}

The idea of methodological incommensurability has been widely criticized. The most widespread response is to appeal to independent criteria that may be applied to competing paradigms. The basic point was made by Israel Scheffler, who noted that Kuhn failed to distinguish between internal standards employed within a paradigm and external standards which are applied to the

\footnotetext{
${ }^{8}$ At this point in the discussion, it is important to bear in mind that we are considering methodological incommensurability in isolation from semantic incommensurability. A certain tension may arise between semantic incommensurability and the epistemic relativist idea that the same belief may be accepted and denied within competing paradigms. For if paradigms are radically incommensurable in the semantic sense, then it is not possible for there to be agreement or disagreement with respect to any particular claims about the world. So it is
} 
paradigm itself (Scheffler, 1967, pp. 84-5). ${ }^{9}$ A variety of attempts have been made to identify external standards that may be applied to competing paradigms, including the progressiveness of research programmes (Lakatos, 1978) and the problem-solving effectiveness of research traditions (Laudan, 1977).

Kuhn's own response was to clarify his view with respect to extraparadigmatic standards. ${ }^{10}$ Where the discussion in Structure emphasized rules of puzzle-solving internal to paradigm, Kuhn later allowed that extraparadigmatic standards play a role in choice of theory or paradigm. As noted in section 2, such extraparadigmatic standards constitute values rather than rules. The values, which include accuracy, simplicity, consistency, breadth and fruitfulness, are open to alternative interpretation on the part of the individual scientists who appeal to them. In addition, there is potential for conflict between values when they are applied to particular theories. Competing theories may be ranked differently on the basis of different values (e.g. one may be simpler though a rival is more accurate). Since the values do not form a fixed hierarchy, scientists may vary with respect to the weights they attach to particular values. As a result of differences in interpretation and weighting, the values which inform scientists' choice of theory do not not possible for scientists in competing paradigms to accept opposing beliefs.

${ }^{9}$ Scheffler does not in fact use the expression 'external standard'. Instead he speaks of 'second-order' standards or standards used at the 'second level'. However, I prefer to speak instead of external standards or extraparadigmatic standards. Speaking of second-order standards is potentially ambiguous, since it can be understood to refer to meta-standards used to judge standards as well as standards used to judge paradigms. In context, it is clear that Scheffler has the latter in mind. To avoid the ambiguity I shall speak either of external or extraparadigmatic standards.

${ }^{10}$ I shall set to one side the interpretative question of whether Kuhn's response to the criticism constitutes a clarification of the view presented in Structure or the development of a new position that was not contained therein. Hoyningen-Huene suggests some elements of Kuhn's later view occur in Structure, e.g. aesthetic factors that attract scientists to a new paradigm (Kuhn, 1996, p. 155-6). For discussion, see Hoyningen-Huene (1993, pp. $240 \mathrm{ff})$. However, he also admits that Kuhn tends to speak of "arguments" rather than "values" at relevant sections of Structure (1993, p. 149, fn. 115). 
constitute an algorithm of theory-choice. It is therefore possible for scientists to disagree with respect to choice of theory on a rational basis, since their opposing choice of theory may be supported on the basis of the common set of values despite the alternative weightings and interpretations of the values.

Strictly speaking, to allow that there may be extraparadigmatic standards of appraisal is to reject methodological incommensurability in the sense that it occurs in Structure. Despite this, scope remains for a form of methodological incommensurability in the context of Kuhn's revised view. As we have just seen, Kuhn claims that individual scientists attach alternative weightings and interpretations to the shared values. According to Kuhn, such variation in the weighting and interpretation of the values reflects irreducibly subjective aspects of the experience of individual scientists. Because of the role played by such subjective factors, it is not possible to resolve the difference in weighting and interpretations between scientists by appeal to any common standards. Thus, there remains a residual form of incommensurability even within the context of Kuhn's later view. ${ }^{11}$

My focus in this paper, however, is the form of methodological incommensurability found in Structure rather than the residual form which occurs in Kuhn's revised view. My interest relates specifically to the relationship of epistemic relativism to the original form of methodological incommensurability. I am interested in epistemic relativism as it arises from

\footnotetext{
${ }^{11}$ For further discussion of the subjective component involved in the weighting and interpretation of value, see Laudan (1996, p. 14). Martin Carrier explicitly considers the subjective components in the application of values to be an instance of methodological incommensurability (Carrier, 2008, p. 276).
} 
considerations about the variability of methodological standards, rather than the role of subjective components of the experience of individual scientists in the application of shared values. ${ }^{12}$

\section{Epistemic justification and paradigm choice}

In the previous section, I considered the common response to methodological incommensurability that there are extraparadigmatic standards that serve as the basis for choice of paradigm. But apart from the issue of whether there are extraparadigmatic standards, there is a further question to be raised about standards. Namely, on what basis are standards justified? Consideration of this question will return us to the topic of relativism.

Kuhn considered questions of epistemic normativity which relate to the justification of standards on at least three occasions. ${ }^{13}$ But in this context I will restrict discussion to Kuhn's treatment of the issue in Structure. As we have already noted, the standards of normal science are restricted to the paradigms from which they derive and are inapplicable to choice between paradigms. Kuhn develops this point by drawing an analogy between scientific revolutions and

\footnotetext{
${ }^{12}$ The question may be raised whether Kuhn's view that there is a set of non-algorithmic values is a relativistic view. I do not regard the view that there is a set of non-algorithmic values as intrinsically relativistic, despite the fact that the view allows for the possibility of rational divergence of opinion between scientists who appeal to the same set of values. Nor does the possibility that there may be multiple sets of adequate values seem to me necessarily to entail a relativistic view. The issue of relativism is not joined until the question of the justification of such values is raised. If it is possible to provide an objective rationale for the values (even multiple sets of values), relativism is avoided. But if the ultimate basis for the values is an arbitrary decision, irrational commitment or social convention, then relativism is the result.

${ }^{13}$ Apart from the remarks in Structure which we are about to consider, Kuhn addressed the issue on at least two other occasions. At one point, he offered an apparently inductive argument from the success of science as described by his model that scientists ought to do what his model says that they in fact do (1970, p. 237). Later he offered a semantic view on which the rationality of science is grounded in the meaning of the term 'science' (2000, p. 214). For discussion, see Nola and Sankey (2007, pp. 285-97).
} 
political revolutions. I will now quote more extensively from a passage quoted previously

(section 2):

Like the choice between competing political institutions, that between competing paradigms proves to be a choice between incompatible modes of community life. Because it has that character, the choice is not and cannot be determined merely by the evaluative procedures characteristic of normal science, for these depend in part upon a particular paradigm, and that paradigm is at issue. When paradigms enter, as they must, into a debate about paradigm choice, their role is necessarily circular. Each group uses its own paradigm to argue in that paradigm's defense. (1996, p. 94)

In the same way that a choice between alternative political institutions may not be made on the basis of procedures employed within a particular institution, the choice between paradigms may not be made on the basis of normal-scientific standards which derive from a particular paradigm. The paradigm-dependent standards of normal science are themselves brought into question in the context of a choice between competing paradigms. Moreover, to the extent that arguments presented on behalf of a paradigm appeal to the paradigm itself in the course of defending it, the arguments presented in support of a paradigm are circular in nature.

Despite the circular character of the debate between paradigms, Kuhn holds that such debate may still prove effective. Advocates of a paradigm may be able to make a strong case for the paradigm by showing what science would be like if the paradigm were to be adopted. But such a case may be "persuasive" at best:

The man who premises a paradigm when arguing in its defense can nonetheless provide a clear exhibit of what scientific practice will be like for those who adopt the new view of nature. That exhibit can be immensely persuasive, often compellingly so. Yet, whatever its force, the status of the circular argument is only that of persuasion. It cannot be made logically or even probabilistically compelling for those who refuse to step into the circle. The premises and values shared by the two parties to a debate over paradigms are not sufficiently extensive for that. As in political revolutions, so in paradigm choice - there is no standard higher than the assent of the relevant community. To discover how scientific revolutions are effected, we shall therefore have to examine not only the impact of nature 
and of logic, but also the techniques of persuasive argumentation effective within the quite special groups that constitute the community of scientists. (1996, p. 94)

In Kuhn's view, it may be possible to persuade scientists to adopt a new paradigm. But persuasive argumentation is unable to conclusively demonstrate the superiority of a paradigm to adherents of a competing paradigm. Arguments presented on behalf of a paradigm fail to be demonstrative because there is too little common ground shared between competing paradigms. No argument for a paradigm can compel the assent of adherents of a competing paradigm since they do not share basic assumptions on which the argument for the new paradigm depends.

It is particularly important for our purposes to note the account of epistemic justification that emerges in the above two passages. In Kuhn's view, methodological standards depend upon a particular paradigm and may not be employed in the choice between competing paradigms. But, given that methodological standards depend upon particular paradigms, the question remains of the ultimate basis for the acceptance of a paradigm. At this stage in the development of Kuhn's thought, the answer to this question cannot be that acceptance of a paradigm is based upon a shared set of scientific values. For Kuhn's account of the role of values in theory-choice does not explicitly emerge until after Structure in response to criticism. Indeed, as we have seen, Kuhn attributes no role to extraparadigmatic standards in the choice between paradigms in Structure.

Rather than appeal to extraparadigmatic standards, the ultimate basis for choice of paradigm is the judgement of the community of scientists. This is the real significance of the analogy that Kuhn draws between scientific and political revolution. The choice between competing paradigms and the decision to adopt one political system over another are alike 
specifically in the sense that "there is no standard higher than the assent of the relevant community". The ultimate basis for the acceptance of a paradigm is simply a matter of social acceptance by a particular group of scientists. The same applies for the justification of the standards employed in normal science, since such standards depend upon the paradigm in which they are employed.

It is for this reason that Kuhn's treatment of choice between paradigms in Structure provides so clear an example of epistemic relativism. For on this account, not only do the norms of epistemic appraisal vary from one paradigm to another, but the basis of the choice between paradigms is merely sociological. There is no ultimate epistemic ground for the choice of paradigm. There is simply a variation in the standards that are adopted by the community of scientists from one paradigm to another. In the context of a given paradigm, scientists are justified in their beliefs on the basis of the normal-scientific standards that are adopted within that paradigm. But the ultimate choice of paradigm is epistemically ungrounded. It is a matter of social acceptance.

\section{Parallels with Pyrrhonism}

Elsewhere I have argued that the principal argument for epistemic relativism derives from the ancient Pyrrhonian problem of the criterion (Sankey 2011 and 2012). The problem of the criterion arises in the context of the attempt to justify an epistemic norm or criterion. In order to 
justify a criterion, appeal may be made to some other criterion. But the question arises of how this other criterion is to be justified. To justify it, appeal may be made to yet another criterion. But, in this way, the attempt to justify the original criterion embarks on an infinite regress. To avoid the regress, appeal may be made to the original criterion. If this occurs, the justification proceeds in a circle. Alternatively, the criterion may be adopted on a dogmatic basis. But in this case the criterion is adopted without justification and is therefore unjustified.

The problem of the criterion is a sceptical device which leads in the hands of the Pyrrhonian sceptics to suspension of belief. However, it may be put to use on behalf of epistemic relativism. For the problem of the criterion reveals that all epistemic norms are unjustified. But if all epistemic norms are unjustified, then no epistemic norm is better justified than any other norm. Thus the choice between alternative epistemic norms is not one for which it is possible to provide an epistemic justification. The choice between alternative norms can be at most an arbitrary decision, made on the basis of irrational commitment, subjective choice or social convention. From an epistemic point of view, there is no fact of the matter about which epistemic norms are correct. Epistemic justification depends upon whatever set of norms happens to be adopted within a particular social group. There is no higher authority than that.

Kuhn does not himself discuss Pyrrhonian scepticism or the problem of the criterion. However, there are two points of overlap between Kuhn's treatment of justification and the problem of the criterion where a significant parallel may be drawn. The first point of overlap relates to the circularity that arises in the course of defending a paradigm. The second relates to the claim that there is no higher standard than the assent of a scientific community. 
To take the first point, there is a close analogy between the circularity of paradigm debate and the role of circularity in the problem of the criterion. The attempt to justify a criterion proceeds in circular fashion if appeal is made to the criterion itself. The circle is most apparent where appeal is made to a criterion in order to resolve dispute about the existence of a criterion. According to Sextus Empiricus, some ancient philosophers held that a criterion exists, others denied that there is a criterion, while the Pyrrhonian suspends judgement about the matter $(P H$, II, 18-21). A criterion is needed in order to resolve the dispute. But on what basis is such a criterion to be adopted? Without the prior adoption of a criterion, there is no basis on which to resolve the dispute about the existence of a criterion. But it is not possible to appeal to any such criterion, since the existence of such a criterion is just what is at issue.

In similar vein, Kuhn argues that debate between paradigms lapses into circularity. Proponents of alternative paradigms appeal to their own paradigm when they argue in defence of the paradigm. In neither the case of justifying a criterion nor in the defence of paradigm does the attempted justification succeed. For the attempted justification is undermined by the circularity that arises in the course of the justification. Rather than justify the criterion or paradigm, such justification begs the question on behalf of that which was meant to be justified. Thus, in view of the circularity that arises, neither the criterion nor the paradigm is able to be provided with a satisfactory justification.

The second point of parallel relates to Kuhn's claim that in scientific revolution there is no higher standard than "the assent of the relevant community". The situation with respect to adoption of a paradigm is strikingly similar to that which arises in relation to the problem of the 
criterion. Apart from circularity, the attempt to provide justification for a criterion gives rise to an infinite regress. One way to respond to the regress that threatens is to terminate the regress at a dogmatic halting-point. This may be done by simply adopting the criterion as an assumption, which means that the criterion is adopted without justification.

A similar situation applies with respect to the adoption of a paradigm. For to say that there is no higher standard than the assent of the scientists who adopt a paradigm is to say that there is no further justification that may be provided for the paradigm. In effect, the scientists who adopt the paradigm without further argument do so as a matter of assumption. In the same way that the sceptical regress of justification is brought to an end at a dogmatic halting-point, the attempt to justify a paradigm reaches an end-point with the assent of the scientists involved. Because the criterion is adopted by assumption, it fails to be justified. Similarly, the adoption of a paradigm by the community of scientists is made without justification.

Despite the fact that Kuhn does not discuss Pyrrhonian scepticism, these two points of parallel between Kuhn's handling of justification and the problem of the criterion have an important implication with respect to treatment of the epistemic relativism found in Structure. Kuhn's considerations relating to the circularity of paradigm debate and lack of justification for adoption of paradigm are fundamentally analogous to those which relate to circularity and the unjustified adoption of criteria highlighted by the Pyrrhonian sceptic. That defence of a paradigm is circular and its adoption unjustified is precisely what one would expect on the basis of the sceptical considerations relating to the justification of criteria. In light of the sceptical nature of Kuhn's considerations about circularity and the dogmatic adoption of paradigms, it is possible to 
respond to the epistemic relativism of Structure on the basis of an anti-sceptical strategy. As I shall indicate in the final section, a particularist response to the problem of the criterion provides the basis for a response to this form of relativism.

\section{Conclusion}

In this paper, I have considered the relationship between the methodological form of incommensurability found in Structure and epistemic relativism due to the variation of epistemic

norms. Epistemic relativism emerges as a consequence of methodological incommensurability because there are no common standards on the basis of which a rational choice between competing paradigms may be made. The view that there are no shared standards of theory appraisal was subjected to severe criticism by influential commentators who argued for the existence of external or extraparadigmatic standards. In later work, Kuhn himself adopted a version of the external standard response with his view that scientists' choice of theory is guided by non-algorithmic values that are broadly characteristic of science. But while appeal to external standards may remove the inference from lack of common standards to epistemic relativism, scope remains for epistemic relativism on the basis of Kuhn's views about epistemic justification.

Though scepticism and relativism tend in opposite directions, we have seen that an argument with sceptical roots may be employed on behalf of the relativist position. Sceptical considerations of circularity and infinite regress which arise with respect to justification form the basis of an argument that no epistemic norm has greater justification than any other. But, given the sceptical provenance of this argument for relativism, it is possible to respond to it on the basis 
of an anti-sceptical strategy. As I have argued elsewhere, an epistemic particularist response to the problem of the criterion of the kind proposed by Roderick Chisholm may serve as the basis for a response to the epistemic relativist.

Chisholm frames the problem of the criterion in terms of an opposition between the question of what we know and the question of how we know. The sceptic takes it to be impossible to answer either question because neither question may be answered without a prior answer to the other. By contrast, the position that Chisholm describes as the methodist position takes the question of how we know as the prior question and proposes criteria of knowledge as a basis for a response to the question of what we know. The position that Chisholm himself favours is the particularist position. The particularist takes the question of what we know to be the prior question. For the particularist, the question of what we know may be answered without first identifying criteria of knowledge.

Rather than require that all items of knowledge be recognized as such on the basis of criteria of knowledge, the particularist starts with concrete instances of knowledge. Epistemological deliberations take off from specific items of knowledge. The attempt to formulate epistemic criteria is a secondary task which follows the prior identification of items of knowledge. The function of epistemic criteria is to reveal the nature of knowledge, rather than to show that we have knowledge. The advantage of the particularist approach is that it avoids the problem of circularity and the threat of an infinite regress which arises if one takes the task of epistemology to be to identify and then justify epistemic criteria. Of course, the particularist 
approach has the disadvantage noted by Chisholm that starting off with instances of knowledge begs the question against the sceptic who challenges our possession of knowledge.

Chisholm was not himself a naturalist. However, the particularist approach to the problem of the criterion fits comfortably within a naturalistic framework. For the naturalist, our possession of knowledge is not taken to be open to serious challenge by the sceptic. The sceptic sets the epistemic bar inappropriately high. Knowledge is a human possession, subject to the ordinary standards and produced by the ordinary practices of common sense and scientific inquiry. Faced with the sceptical challenge, the naturalist simply assumes that we have knowledge. But, though this may beg the question against the sceptic, this is not serious question-begging since the sceptical challenge is not to be taken seriously as a challenge to our actual possession of knowledge.

Once it is assumed that we do have knowledge, and, moreover, that we are in possession of particular instances of knowledge, then the way is clear to a naturalistic response to the relativist based on the particularist response to scepticism. We may draw upon particular instances of knowledge that we possess as the basis for empirical evaluation of the reliability of various epistemic norms that may be proposed. It is possible to conduct an empirical assessment of a proposed epistemic norm by determining whether use of the norm leads to the production of particular items of knowledge. Alternative epistemic norms may be evaluated on a comparative basis by determining whether one norm produces knowledge more reliably than another. Given the possibility of an empirical assessment of the reliability of epistemic norms, we may reject the relativist claim that no epistemic norm has greater justification than any other. For it may be 
possible to show that some proposed epistemic norms have greater reliability than other proposed norms. Hence, the particularist may join forces with the naturalist to provide a response to the relativist to the effect that not all epistemic norms are on a par.

Thus, we may add to Kuhn's own endorsement of external standards a rejection of the sceptical basis for the epistemic relativism characteristic of Kuhn's approach in Structure. It is not just the case that the appeal to external standards provides a sufficient basis to respond both to methodological incommensurability and the form of epistemic relativism that arises from such incommensurability. In addition, the particularist response to the Pyrrhonian problem of the criterion provides the basis for a reliabilist rebuttal of the relativist view that no epistemic norm has greater justification than any other. Not only are there external standards of theory appraisal, but it is possible to determine that some standards are epistemically better justified than others. Thus, the epistemic relativist aspects of Structure may be completely repudiated. There is no basis for relativism either in the methodological form of incommensurability or in the circularity or dogmatism that arises in the justification of paradigms. 


\section{References}

Carrier, M (2008) The Aim and Structure of Methodological Theory. In: Soler L, Sankey H, Hoyningen-Huene P (eds) Rethinking Scientific Change and Theory Comparison, Springer, Dordrecht

Doppelt, G (1982) Kuhn's Epistemological Relativism: An Interpretation and Defense. In: Krausz M, Meiland JW (eds) Relativism: Cognitive and Moral, University of Notre Dame Press, Notre Dame

Feyerabend, P (1993) Against Method. $3^{\text {rd }}$ edn. Verso, London

Hoyningen-Huene, P (1993) Reconstructing Scientific Revolutions: Thomas S. Kuhn's Philosophy of Science. University of Chicago Press, Chicago

Hoyningen-Huene, P, Sankey H (eds) (2001) Incommensurability and Related Matters. Kluwer, Dordrecht

Kuhn, TS (1970) Reflections on My Critics. In: Lakatos I, Musgrave A (eds) Criticism and the Growth of Knowledge. Cambridge University Press, Cambridge

Kuhn, TS (1977) The Essential Tension. University of Chicago Press, Chicago

Kuhn, T S (1996) The Structure of Scientific Revolutions, $3^{\text {rd }}$ edn. University of Chicago Press, Chicago

Kuhn, TS (2000) Rationality and Theory Choice. In: The Road Since Structure. University of Chicago Press, Chicago 
Lakatos, I (1978) Falsification and the Methodology of Scientific Research Programmes. In: Worrall J, Currie G (eds) The Methodology of Scientific Research Programmes: Philosophical Papers, Volume I. Cambridge University Press, Cambridge

Laudan, L (1977) Progress and its Problems. Routledge and Kegan Paul, London

Laudan, L (1996) Beyond Positivism and Relativism. Westview Press, Boulder, Co.

Nola, R, Sankey H (2007) Theories of Scientific Method: An Introduction. Acumen Press, Chesham

Sankey, H (2010) Witchcraft, Relativism and the Problem of the Criterion. Erkenntnis 72: 1-16

Sankey, H (2011) Epistemic Relativism and the Problem of the Criterion. Studies in History and Philosophy of Science 42: 562-570

Sankey H (2012) Scepticism, Relativism and the Argument from the Criterion. Studies in History and Philosophy of Science 43: 182-190

Scheffler, I (1967) Science and Subjectivity. Bobbs-Merrill, Indianapolis

Sextus Empiricus ( $P H$ [1933]) Outlines of Pyrrhonism (translated by RG Bury). Harvard University Press, Cambridge, Mass.

Shapere, D (1984) Reason and the Search for Knowledge. Kluwer, Dordrecht

Siegel, H (1987) Relativism Refuted. Reidel, Dordrecht 


\section{University Library}

\section{- M M N E R VA A gateway to Melbourne's research publications}

Minerva Access is the Institutional Repository of The University of Melbourne

Author/s:

Sankey, $\mathrm{H}$

Title:

Methodological Incommensurability and Epistemic Relativism

Date:

2013-04-01

Citation:

Sankey, H. (2013). Methodological Incommensurability and Epistemic Relativism. TOPOIAN INTERNATIONAL REVIEW OF PHILOSOPHY, 32 (1), pp.33-41. https://doi.org/10.1007/ S11245-012-9139-6.

Persistent Link:

http://hdl.handle.net/11343/282906 